\title{
Patient Satisfaction with Procedural Sedation in the Emergency Department
}

\section{Investigators}

Olivia Grover Johnson BSci MD

Department of Medicine, University of Melbourne, Victoria, Australia

o.groverjohnson@gmail.com

David McD Taylor MBBS MD MPH DRCOG FACEM

Emergency Department, Austin Hospital, Heidelberg, Victoria, Australia

Department of Medicine, University of Melbourne, Victoria, Australia

David.Taylor@austin.org.au

Marina Lee BBioMed MD

Department of Medicine, University of Melbourne, Victoria, Australia lee.marina90@gmail.com

Juen-Li Ding BBioMed MD

Department of Medicine, University of Melbourne, Victoria, Australia juenli.ding@gmail.com

Aadith Ashok BBioMed MD

Department of Medicine, University of Melbourne, Victoria, Australia aadithashok7@gmail.com

Damian Johnson BBioMed MD

Department of Medicine, University of Melbourne, Victoria, Australia damian.jg.johnson@gmail.com

Daniel Peck BBioMed MD

Department of Medicine, University of Melbourne, Victoria, Australia dpeck012@gmail.com

Jonathan Knott MBBS FACEM PhD

Emergency Department, Royal Melbourne Hospital, Parkville, Victoria, Australia Department of Medicine, University of Melbourne, Victoria, Australia Jonathan.Knott@mh.org.au

Laurence Weinberg MBBCh, BSc, MD, MRCP, Dip Periop Crit Care Echo, FANZCA Department of Anaesthesia, Austin Hospital, Heidelberg, Victoria, Australia Department of Medicine, University of Melbourne, Victoria, Australia Laurence.WEINBERG@austin.org.au

This is the author manuscript accepted for publication and has undergone full peer review but has not been through the copyediting, typesetting, pagination and proofreading process, which may lead to differences between this version and the Version of Record. Please cite this article as doi: $10.1111 / 1742-6723.12762$

This article is protected by copyright. All rights reserved. 


\section{Author contributions}

DT, OGJ and LW conceived and designed the study. DT obtained ethics approval. DT and JK supervised the conduct of the study and data collection at their respective sites. OGJ, ML, JLD, AA, DP and DP undertook all data collection. DT analyzed the data. DT, OGJ, JK and LW interpreted the results. All authors drafted the manuscript and contributed substantially to its revision. DT takes responsibility for the paper as a whole.

\section{Address for Correspondence:}

Professor David Taylor

Emergency Department, Austin Hospital,

Studley Road, Heidelberg, Victoria, Australia 3084

Phone (W) +61 394964711

David.Taylor@austin.org.au

Word count: Abstract 248, Text 2,494

\section{Funding Sources}

The project was unfunded

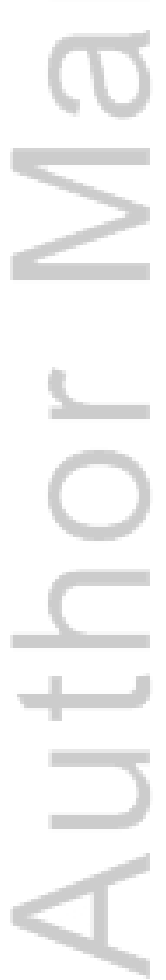




\begin{abstract}

\section{Objective}

To determine patient satisfaction with procedural sedation as a function of nature of the procedure and depth of sedation

\section{Method}

We undertook a prospective observational study of adult patients who received procedural sedation in two Emergency Departments (20 month period). The level of sedation was determined by an investigator, using the Observers Assessment of Anaesthesia/Sedation Scale ( $1=$ awake to $6=$ no response to noxious stimuli). Patient satisfaction was measured with the Iowa Satisfaction with Anaesthesia Scale after full recovery. This was self-administered, comprised 11 items (e.g. I felt pain) and has a score range of -3 (poor satisfaction) to +3 (very satisfied).

\title{
Results
}

163 patients were enrolled (51.2\% male, mean age 50.7 years). The median (IQR) satisfaction score was $2.7(0.7)$. Patient satisfaction was lower among patients who had orthopaedic procedures (median 2.6 versus $2.8, \mathrm{p}<0.01$ ) and among patients who had a pre-sedation opioid (2.6 versus $2.8, p=0.03$ ). Satisfaction was positively correlated with deeper sedation (Spearman's correlation coefficient $0.49, \mathrm{p}<0.001$ ). Satisfaction also differed significantly between the four most common sedation regimens $(\mathrm{p}<0.001)$. It was greatest among those who were administered propofol \pm fentanyl and least among those who were administered nitrous oxide \pm opioid. Patients sedated with propofol \pm fentanyl had the greatest depths of sedation. There was no difference in satisfaction among patients who were/were not sedated by a consultant (median 2.6 and 2.7 , respectively, $p=0.84$ ).

\section{Conclusion}

This article is protected by copyright. All rights reserved. 
Generally, the level of patient satisfaction is high. Greater satisfaction is associated with deeper sedation, sedation with propofol, and non-orthopaedic procedures.

\section{Key Words}

Patient Satisfaction, Patient Experience, Procedural Sedation, Conscious Sedation, Emergency Department

This article is protected by copyright. All rights reserved. 


\section{INTRODUCTION}

Procedural sedation in the ED is common and is regularly undertaken for the management of painful fractures and dislocations. ${ }^{1}$ However, the choice of sedation drug regimens varies considerably world-wide. ${ }^{1-5}$ The Australian and New Zealand College of Anaesthetists (ANZCA) guidelines on procedural sedation ${ }^{6}$ indicate that benzodiazepines (e.g. midazolam) for sedation and opioids (e.g. fentanyl) for analgesia are commonly used. Additionally, ANZCA endorses the use of propofol if the practitioner is experienced in its use and does not undertake the procedure itself. The ANZCA guidelines ${ }^{6}$, however, do not make recommendations for the use of specific anaesthetic or analgesic agents. Guidelines from the United States $^{2}$, United Kingdom ${ }^{3}$, Canada $^{7}$ and Europe ${ }^{8}$, while providing broad principles for procedural sedation (e.g. aim, setting, staff, and monitoring) are also non-prescriptive.

Recently, Bell et al. ${ }^{1}$, in a large Australian study, reported that sedation practices vary both within and between EDs, with a wide range of drugs and drug combinations commonly utilised. Risk factors for sedation-related adverse events ${ }^{9}$ and factors associated with procedure failure $^{10}$ are well described. While there are a number of reports of ED procedural sedation, the large majority relate to drug safety and efficacy. ${ }^{1,11,12}$ Presently, there is a paucity of literature on patient satisfaction and awareness. This is despite recommendations for research on qualitative aspects of the patient experience. ${ }^{1,6}$

Our primary objective was to explore ED procedural sedation from the patients' perspective. Specifically, it evaluated patient satisfaction as a function of the type of procedure, the depth of sedation, the drugs administered and the designation of the sedator. The findings of this 
exploratory study will inform the development of more definitive studies from the patients' perspective.

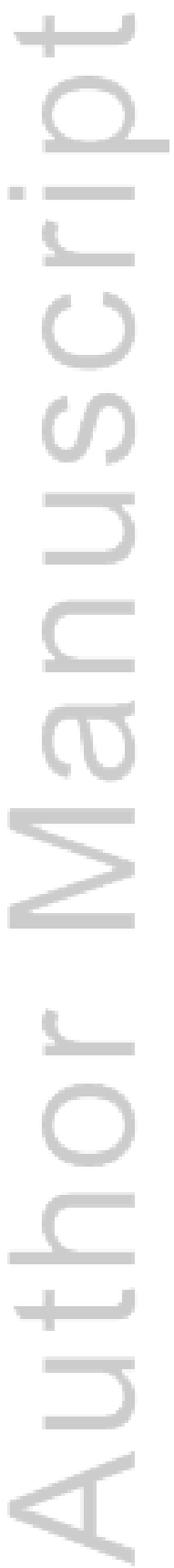

This article is protected by copyright. All rights reserved. 


\section{METHODS}

This was a prospective, observational study undertaken in a metropolitan, adult/paediatric, tertiary referral ED (annual census 77,000) and an inner city, adult-only, tertiary referral ED (annual census $\sim 60,000$ ). There were two data collection periods, determined by the availability of research staff: July 2007 to October 2008 and February 2015 to June of 2015 (total 20 months). The study was approved by one centre's Health Human Research and Ethics Committee.

A convenience sample of participants was recruited when an investigator was available (usually weekdays 08:00 and 22:00). Inclusion criteria were age 16 years or more, requiring a painful procedure in the ED and the administration of a sedative/anaesthetic and/or an analgesic agent(s) for the procedure. Exclusion criteria were medical reasons (major injury, on-going pain or discomfort) or communication difficulties (poor English, cognitive impairment).

An investigator observed all procedures and recorded patient demographics, the nature and outcome of the procedure, the sedation drugs regimen, the maximum depth of sedation and adverse events. However, he/she did not assist with the sedation. Depth of sedation was measured using the Observers Assessment of Anaesthesia/Sedation Scale (OAAS) ${ }^{11}$ (see Box). This is a validated, widely used, ordinal scale employed either during or immediately after completion of the procedure.

Upon full recovery from the sedation (GCS 15, talking normally), patients were advised of the study and invited to complete the self-administered study questionnaire. Participation indicated implied consent. Assistance was provided if required. 
Patient satisfaction was measured using the Iowa Satisfaction with Anaesthesia Scale (ISAS) $^{12}$ (see Box). This was designed and validated for patients in the surgical postanaesthesia setting. For each item, the patient marked one of six response options. Before data analysis, scores for undesirable items (e.g. I felt pain) were reversed (the negative score became a positive score). So, disagreement with an undesirable item resulted in an increase in the total score. A totally satisfied patient would have a total score of +3 on all items and a mean score of +3 . The range of possible mean scores ranges from -3 to +3 .

Awareness was defined by the ability of the patient to recall, with or without prompting, any event between induction of sedation and recovery of consciousness. It was measured using the Brice Questionnaire ${ }^{13}$, modified by Liu et al.. ${ }^{14}$ Five simple questions were asked (see Box) and the results are reported descriptively. For this study, four questions were slightly modified for the ED setting i.e. 'operation' was replaced by 'procedure'. Recall data were not collected in the first data collection period.

The primary study outcome was overall patient satisfaction with their procedural sedation. The secondary study outcome was depth of sedation.

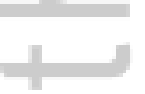

All patients meeting the entrance criteria when an investigator was available were enrolled. No a priori sample size was calculated as enrolment was restricted by defined study periods and the expected enrolment rate was not known. However, a post hoc power calculation indicated adequate power to demonstrate a statistically significant difference between patients who received propofol only and nitrous oxide \pm opioid, for both depth of sedation (power 0.8 ) and patient satisfaction (power 0.95) (alpha 0.05, 2-sided). 
Most data are reported descriptively as frequency (\%), median (IQR) or mean (SD). The Mann-Whitney U and Kruskal-Wallis tests were employed to compare the non-parametric, continuous variables of two groups and multiple groups, respectively. The Spearman Correlation and Chi square tests were employed to examine the association between nonparametric, ordinal variables (ISAS and OAAS scores) and proportions, respectively. All analyses were undertaken using SPSS for Windows statistical software (version 22.0, SPSS Inc., Chicago, Illinois, USA). The level of significance was 0.05 .

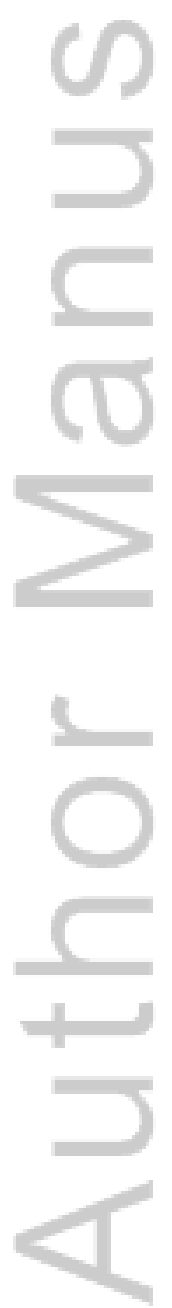

This article is protected by copyright. All rights reserved. 


\section{RESULTS}

One hundred and sixty three patients were enrolled: 84 (51.5\%) were male, the mean (SD) age and weight were $50.7(21.4)$ years and $80.7(16.7) \mathrm{kg}$, respectively.

A range of procedures was undertaken although lower limb orthopaedic procedures, shoulder relocations and cardioversion were the most common (Table 1). Overall, procedures were short with a median (IQR) time from induction until wakening of $8(8)$ minutes. The median (IQR) time from completion of the procedure until wakening was 3 (3.25) minutes.

More than one half of patients were administered a pre-sedation opioid (Table 2). In almost all cases $(87.6 \%)$, this was parenterally. A wide range of sedation regimens were administered although the most common was propofol \pm fentanyl.

Patient satisfaction data were obtained from 156 (95.7\%) patients. Overall, the median (IQR) satisfaction score was $2.7(0.7)$ but ranged from -0.4 to 3.0 (Figure 1). Patients who had an orthopaedic procedure and patients who were administered a pre-sedation opioid were significantly less satisfied (Table 2). Significantly more patients who had an orthopaedic procedure were administered a pre-sedation opioid (92 [80\%] versus 5 [10.4\%], difference in proportions $69.6 \%$ [95\%CI 56.8, 82.4], $\mathrm{p}<0.001)$.

Patient satisfaction correlated positively with depth of sedation: Spearman's correlation coefficient $0.49(p<0.001$, Figure 2). Also, satisfaction for the four major sedation regimens differed significantly. Satisfaction was greatest among patients administered propofol \pm fentanyl and least among those administered nitrous oxide \pm opioid (Table 2). Satisfaction among patients who were/were not sedated by a consultant did not differ. 
Nine patients had very low satisfaction scores (d1.0). Each patient had an orthopaedic procedure (limb fracture, shoulder or hip reduction) except one who was administered nitrous oxide to facilitate a digital ring block. The drug regimens of these patients included propofol/fentanyl (2 patients), nitrous oxide only (2), propofol only (1), ketafol (ketamine/propofol combination, 1), ketamine only (1), midazolam only (1) and nitrous oxide/fentanyl (1). Five patients had sedation scores of 6 and single patients had scores of 5 , 4, 3 and 2. Their median (IQR) and mean (SD) sedation scores were 6 (2) and 4.9 (1.5), respectively.

Overall, the median (IQR) depth of sedation score was 6 (1) but ranged from 1 to 6 (Figure 3). Although the median (IQR) values were the same, patients who had an orthopaedic procedure and patients who were administered a pre-sedation opioid had a significantly lower depth of sedation (Table 2). Patients who an orthopaedic procedure and those who were administered a pre-sedation opioid had lower mean depths of sedation (5.4 versus 5.8 and 5.4 versus 5.7, respectively).

The depths of sedation for the four major sedation regimens differed significantly (Table 2). Depth was greatest among patients administered propofol \pm fentanyl and least among those administered nitrous oxide \pm opioid. The depth of sedation did not differ between patients who were/were not sedated by a consultant.

Forty patients completed the Brice questionnaire and responses varied. The last things that patients remembered before the sedation were most commonly speaking to/listening to/watching the doctor or nursing staff; and also watching the insertion of the 
cannula/administration of sedative drugs. After the procedure, the first things that were remembered were most commonly happiness, feeling less pain and greater comfort, the nurse asking a question, and new dressings or plastering. Twenty eight (70.0\%) patients remembered nothing between induction and awakening; nine $(22.5 \%)$ had vague, unclear or distorted memories; two (5.0\%) reported being awake with a clear memory; and one $(2.5 \%)$ patient did not provide a response. Four $(10.0 \%)$ of patients reported dreams during the procedure. Nine patients did not believe there was a bad (worst) thing about their procedure. However, seven reported this was the pain before the procedure; six reported the pain of IV cannulation; five described fear and anxiety; and two reported it was the pain during the procedure itself.

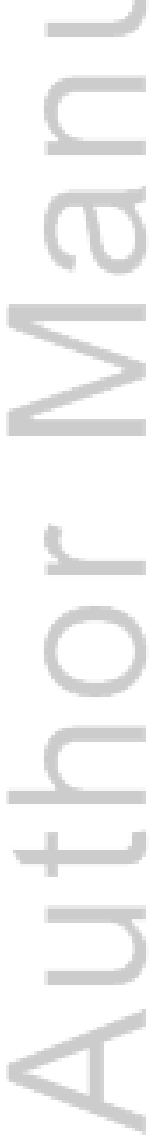

This article is protected by copyright. All rights reserved. 


\section{DISCUSSION}

Overall, this study found that the level of patient satisfaction with procedural sedation is high. The finding that satisfaction was associated with depth of sedation was expected. A sedation score of six (non-responsive to noxious stimuli) is tantamount to general anaesthesia with the patient much less likely to be aware of the procedure or the associated pain. The propofol regimens provided the deepest sedation and it is not surprising that they were also associated with greater patient satisfaction. Evidence for this is the moderate correlation between depth of sedation and satisfaction. Swann et al. ${ }^{15}$ also reported a significant positive correlation between the administration of propofol and patient satisfaction, although their correlation coefficient was small (0.2).

The association between depth of sedation and patient satisfaction is consistent with other studies with similar patient characteristics, procedures and sedation regimens. ${ }^{15,16,17}$ However, these early reports had either a small sample size ${ }^{16}$, a low correlation coefficient ${ }^{15}$ or patient satisfaction as a secondary aim that was measured with an un-validated assessment tool ${ }^{15,17}$. Presently, there are no patient satisfaction tools that have been specifically validated for procedural sedation in the ED setting. ${ }^{18}$ Only the ISAS scale, developed by Dexter et al. ${ }^{12}$, has been identified as being reasonably applicable in this setting. ${ }^{18}$

Coyle et al. ${ }^{19}$ investigated the relationships between depth of sedation, patient recall and patient satisfaction, albeit in the setting of general anaesthesia for surgery. They found that satisfaction was high among patients with no memory of the operation but lower among patients who had recall of pain or being awake and unable to communicate. Most of our patients reported no memory of the procedure, and satisfaction overall was good. However, our study was not designed to examine the association between recall and patient satisfaction. 
In this study, there were some patient groups where management could be improved. Patients having an orthopaedic procedure are at risk of being less satisfied. Orthopaedic injuries and procedures can be very painful and it is not surprising that the large majority of these patients were administered a pre-sedation opioid. This is consistent with the findings of Bell et al. ${ }^{1}$ who reported that parenteral opioids are the most commonly administered pre-sedation drugs. It is likely that it was the orthopaedic procedure itself and not the administration of the presedation opioid that resulted in these patients being less satisfied.

The nine patients who had very low satisfaction scores are noteworthy. All but one of these patients had an orthopaedic procedure and only four were administered propofol. They were at risk, therefore, of lower satisfaction scores. Although five patients had sedation scores of six, it is possible that a range of other confounding variables impacted upon their satisfaction e.g. the quality of the pre-procedure analgesia.

This study suggests that to maximize the chance of a positive experience for the patient, deep sedation is required. However, deep sedation has been associated with a greater frequency of adverse events including airway and breathing compromise and aspiration. ${ }^{9}$ This highlights the importance of undertaking these procedures in a department well-resourced both for staffing seniority and monitoring.

The designation of the sedating doctor was not associated with either the depth of sedation or patient satisfaction. At least for these outcome variables, these findings suggest that nonconsultant ED doctors are providing appropriate clinical management of patients undergoing procedural sedation. This is encouraging, especially when considered with the results of a 
report that the rate of adverse events is also unaffected by the doctor designation. ${ }^{9}$

The large majority of patients were not affected by undesirable recall of the procedure or events. While this is encouraging, the responses of some patients highlight management variables that could be have been improved including pre-procedural analgesia, reassurance and depth of analgesia.

This study has important limitations. The convenience sampling undertaken may have introduced selection bias although there is no reason to believe that sedation management differed out of hours. Although validated, the OAAS tool is partly subjective and liable to measurement bias. However, the number of investigators using this tool was small and each was very familiar with its use. Similarly, the ISAS tool was developed for use in general anaesthesia and its value of its use in the ED is questionable.

As the data were very skewed, the median values do not reflect the underlying data distributions well. A large range of confounding variables may have affected our results including patient demographics and previous experience, pre-hospital analgesia, splinting and other first aid measures, door to procedure time, and the skill of the doctor undertaking the procedure. Our sample size was relatively small and data were not collected on a number of confounding variables. This precluded regression analysis to account for the confounding.

As patients were only enrolled at two EDs, the external validity of the study is questionable. In a national ED sedation study, Bell et al. ${ }^{1}$ reported that $60.3 \%$ of patients were male and that the mean patient age was 39.2 years. Our study enrolled fewer males $(51.5 \%)$ and had an older population (mean age 50.7 years). We cannot extrapolate our findings to procedural 
sedation for more complex procedures or to paediatric, very old, or critically ill ED patients.

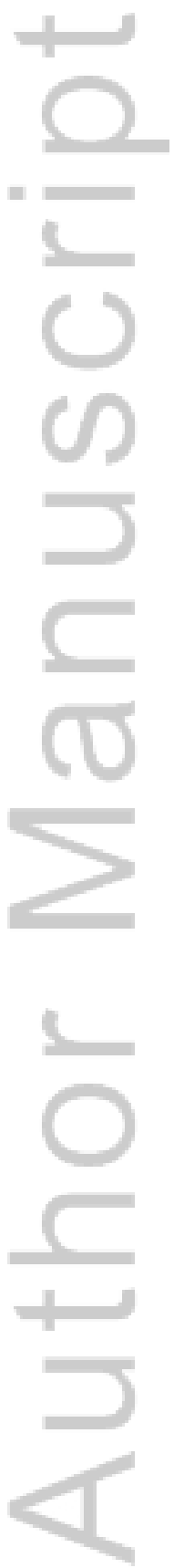

This article is protected by copyright. All rights reserved. 


\section{CONCLUSION}

Patient satisfaction with procedural sedation was generally good. However, greater satisfaction was associated with deeper sedation, sedation with propofol, no pre-sedation opioid and non-orthopaedic procedures. The sedator designation does not affect either the depth of sedation or patient satisfaction. Although most patients undergoing an orthopaedic procedure are administered a pre-sedation opioid, their overall depth of sedation is less and this is reflected in lower satisfaction scores. These patients should receive adequate presedation analgesia and have a deep level of sedation. This will most likely achieved with a sedation regimen containing propofol. A large multi-centre study is recommended to explore in greater detail the variables associated with procedural sedation satisfaction. The variables collected should include the many confounding variables not examined in this study. Multivariate regression analysis is recommended to determine the variables that independently impact upon patient satisfaction.

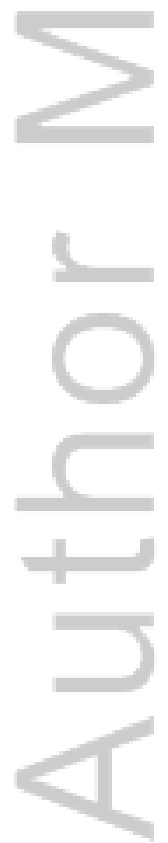

This article is protected by copyright. All rights reserved. 


\section{REFERENCES}

1. Bell A, Taylor DMcD, Holdgate A et al. Procedural sedation practices in australian emergency departments. Emerg Med Australas 2011; 23: 458-65

2. Godwin SA, Burton JH, Gerardo CJ et al. Clinical policy: procedural sedation and analgesia in the emergency department. Ann Emerg Med 2014; 63: 247-258

3. Adams ST, Woods C, Lyall H, Higson M. Standards of practice in UK emergency departments before, during and after conscious sedation. Emerg Med J 2008; 25: 728-371 4. Duncan RA, Symington L, Thakore S. Sedation practice in a Scottish teaching hospital emergency department. Emerg Med J 2006; 23: 684-686

5. Bawden J, Villa-Roel C, Singh M et al. Procedural sedation and analgesia in a Canadian ED: a time-in-motion study. Am J Emerg Med 2011; 29: 1083-1088

6. Australian and New Zealand College of Anaesthetists. Guidelines on sedation and/or analgesia for diagnostic and interventional medical, dental or surgical procedures. 2014. Available at http://www.anzca.edu.au/documents/ps09-2014-guidelines-on-sedation-and-oranalgesia (last accessed August 17, 2016)

7. Eichhorn V, Henzler D, Murphy MF. Standardizing care and monitoring for anesthesia or procedural sedation delivered outside the operating room. Curr Opin Anaesthes 2010; 23: $494-499$

8. Knape. Guidelines for sedation and/ or analgesia by non-anaesthesiology doctors. Euro $J$ Anaesthes 2007; 24: 563-567

9. Taylor DMcD, Bell A, Holdgate A et al. Risk factors for sedation-related events during procedural sedation in the emergency department. Emerg Med Australas 2011; 23: 466-473 10. Holdgate A, Taylor DMcD, Bell A et al. Factors associated with failure to successfully complete a procedure during Emergency Department sedation. Emerg Med Australas 2011; 23: $474-478$ 
11. Chernik DA, Gillings D, Laine $\mathrm{H}$ et al. Validity and reliabilty of the observer's assessment of alertness/sedation scale: study with intravenous midazolam. J Clin Psychopharmacol 1990; 10: $244-251$

12. Dexter F, Aker J, Wright WA. Development of a measure of patient satisfaction with monitored anesthesia care: the Iowa Satisfaction with Anesthesia Scale. Anesthesiology 1997; 87: $865-873$

13. Brice DD, Hetherington RR, Utting JE. A simple study of awareness and dreaming during anaesthesia. Br J Anaesth 1970; 42: 535-542

14. Liu WHD. Incidence of awareness with recall during general anaesthesia. Anaesthesia 1991; 46: 435-437

15. Swann A, Williams J, Fatovich DM. Recall after procedural sedation in the emergency department. Emerg Med J 2007; 24: 322-324

16. Freeston JA, Leal A, Gray A. Procedural sedation and recall in the emergency department: the relationship between depth of sedation and patient recall and satisfaction (a pilot study). Emerg Med J 2012; 29: 670-672

17. Miner JR, Biros MH, Heegaard W, Plummer D. Bispectral electroencephalographic analysis of patients undergoing procedural sedation in the emergency department. Acad Emerg Med 2003; 10: 638-643

18. Barnett SF, Alagar RK, Grocott MPW, Giannaris S, Dick JR, Moonesinghe SR. PatientSatisfaction Measures in Anesthesia Qualitative Systematic Review. Anaesthesiology 2013; 119: $452-478$

19. Coyle TT, Helfrick JF, Gonzalez ML, Andresen RV, Perrott DH. Office-based ambulatory anesthesia: Factors that influence patient satisfaction or dissatisfaction with deep sedation/general anesthesia. J Oral Maxillofac Surg 2005; 63: 163-172 
Box. Scale items and scores and Awareness questionnaire items

\section{Observers Assessment of Anaesthesia/ Sedation Scale ${ }^{11}$ :}

Scale items and scores

- Responded readily to name spoken in normal tone

(score 1)

- Lethargic response to name spoken in normal tone

- Responded only after name called loudly and repeatedly

- Responded only after mild prodding or shaking

- Did not respond to mild prodding or shaking

- Did not respond to noxious (painful) stimulus

\section{Iowa Satisfaction with Anaesthesia Scale ${ }^{12}$ :}

Scale items

- I threw up or felt like throwing up

- I would have the same anaesthetic again

- I itched

- I felt relaxed

- I felt pain

- I felt safe

- I was too hot or cold

- I was satisfied with anaesthetic care

- I felt pain during surgery

- I felt good

- Ihurt

Response options and scores

- Disagree very much (score -3)

- Disagree moderately (score -2)

- Disagree slightly (score -1)

- Agree slightly (score +1$)$

- Agree moderately (score +2$)$

- Agree very much (score +3$)$

Brice Questionnaire $^{13}$, modified by Liu et al. ${ }^{14}$ :

- What was the last thing you remember before you went to sleep for your procedure?

- What is the first thing you remember after your procedure?

- Do you remember anything in between these periods?

- Did you dream during your procedure?

- What was the worst thing about your procedure? 
Table 1: Nature of the procedures undertaken

Type of procedure

Orthopoedic procedure

lower limb
upper limb
shoulder dislocation relocation
orthopaedic other n

$(\%)$

Other procedure

cardioversion

36

intercostal catheter insertion

5

3

foreign body removal

2

2

27

41

3

incision and drainage

other"

163

total

163

$(100.0)$

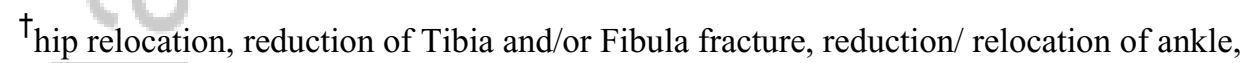
reduction of knee (patella) dislocation

$\ddagger_{\text {reduction of humerus fractures, reduction/relocation of elbow, reduction of forearm }}$ fractures (including Colles fracture), reduction/ relocation of wrist, relocation of upper limb digit dislocations

$\S_{\text {temporo-mandibular joint reduction, nasal bone reduction }}$

$\pi_{\text {manual faecal disimpaction, ring block }}$

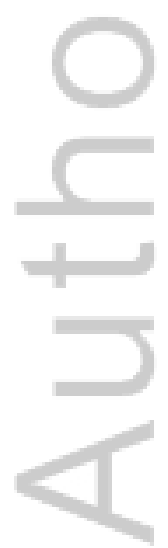

This article is protected by copyright. All rights reserved. 
Table 2. Depth of sedation and patient satisfaction for procedure, pre-sedation and sedation drugs, and sedator designation

\begin{tabular}{|c|c|c|c|c|c|}
\hline \multirow{2}{*}{ variable } & \multirow[b]{2}{*}{$\mathrm{n}(\%)$} & \multicolumn{2}{|c|}{ depth of sedation } & \multicolumn{2}{|c|}{ patient satisfaction $^{\dagger}$} \\
\hline & & $\begin{array}{c}\text { median } \\
\text { (IQR) }\end{array}$ & $\mathrm{p}$ & $\begin{array}{c}\text { median } \\
\text { (IQR) }\end{array}$ & $\mathrm{p}$ \\
\hline$\$$ & & & & & \\
\hline \multicolumn{6}{|l|}{ type of procedure } \\
\hline orthopoedic & $115(70.6)$ & $6(1)$ & \multirow{2}{*}{$<0.01$} & $2.6(1.0)$ & \multirow{2}{*}{$<0.01$} \\
\hline other & $48(29.4)$ & $6(1)$ & & $2.8(0.0)$ & \\
\hline \multicolumn{6}{|l|}{ pre-sedation opioids } \\
\hline any opioid pre-sedation ${ }^{\ddagger}$ & $97(59.5)$ & $6(1)$ & \multirow{2}{*}{0.02} & $2.6(0.8)$ & \multirow{2}{*}{0.03} \\
\hline no pre-sedation opioid & $66(40.5)$ & $6(1)$ & & $2.8(0.6)$ & \\
\hline \multicolumn{6}{|l|}{ common sedation regimens } \\
\hline propofol only & $60(36.8)$ & $6(1)$ & \multirow{3}{*}{$<0.001$} & $2.7(0.7)$ & \multirow{5}{*}{$<0.001$} \\
\hline propofol with fentanyl only & $47(28.8)$ & $6(1)$ & & $2.8(0.8)$ & \\
\hline nitrous oxide \pm opioid & $21(12.9)$ & $5(1)$ & & $2.2(1.0)$ & \\
\hline midazolam \pm opioid & $12(7.4)$ & $5(1)$ & & $2.6(0.5)$ & \\
\hline other $^{\S}$ & $23(14.1)$ & - & & - & \\
\hline \multicolumn{6}{|l|}{ sedator designation } \\
\hline consultant & $85(52.1)$ & $6(1)$ & \multirow{2}{*}{0.99} & $2.6(0.7)$ & \multirow{2}{*}{0.84} \\
\hline other practitioner" & $78(47.9)$ & $6(1)$ & & $2.7(0.8)$ & \\
\hline
\end{tabular}

$\dagger_{\text {satisfaction data available for } 156 \text { patients }}$

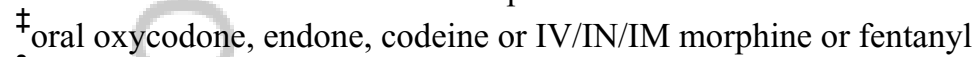

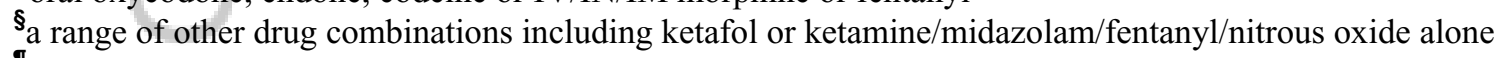

$\pi_{\text {registrar, resident, nurse practitioner }}$ 
Figure 1. Overall patient satisfaction with sedation (mean ISAS score for each patient)

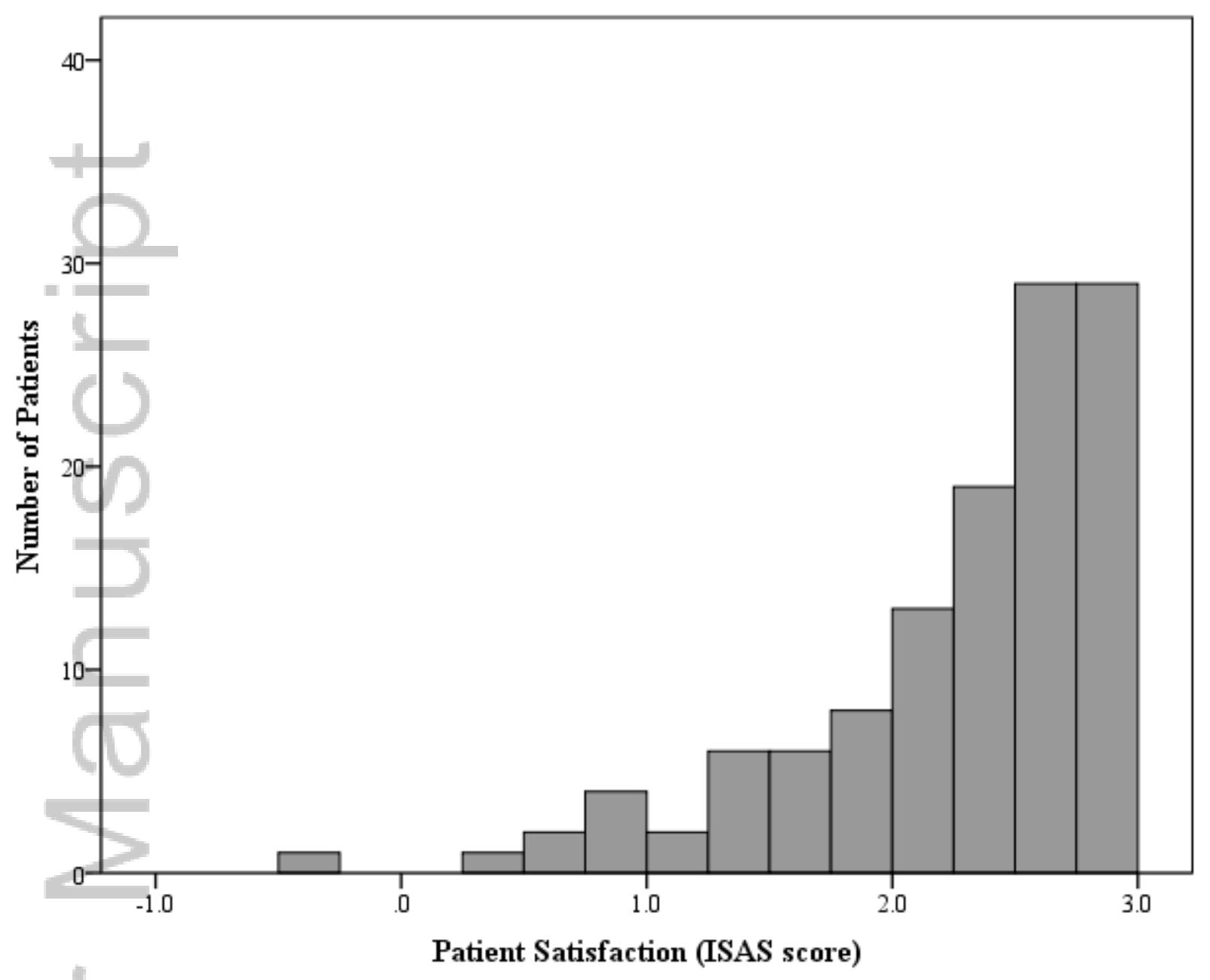

This article is protected by copyright. All rights reserved. 
Figure 2. Patient satisfaction (ISAS score) as a function of the Depth of Sedation

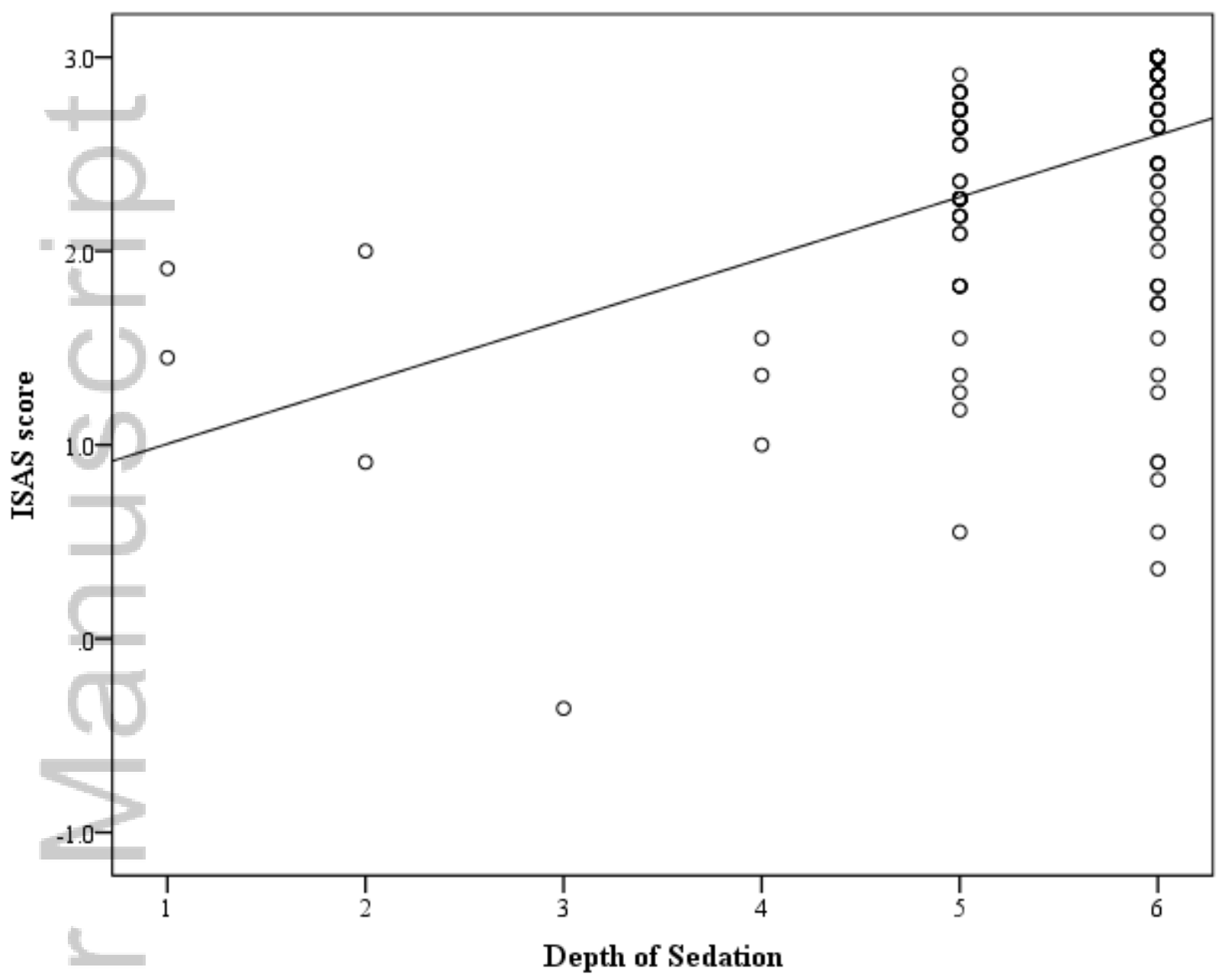

This article is protected by copyright. All rights reserved. 
Figure 3. Frequency of OAAS Depth of Sedation Scores

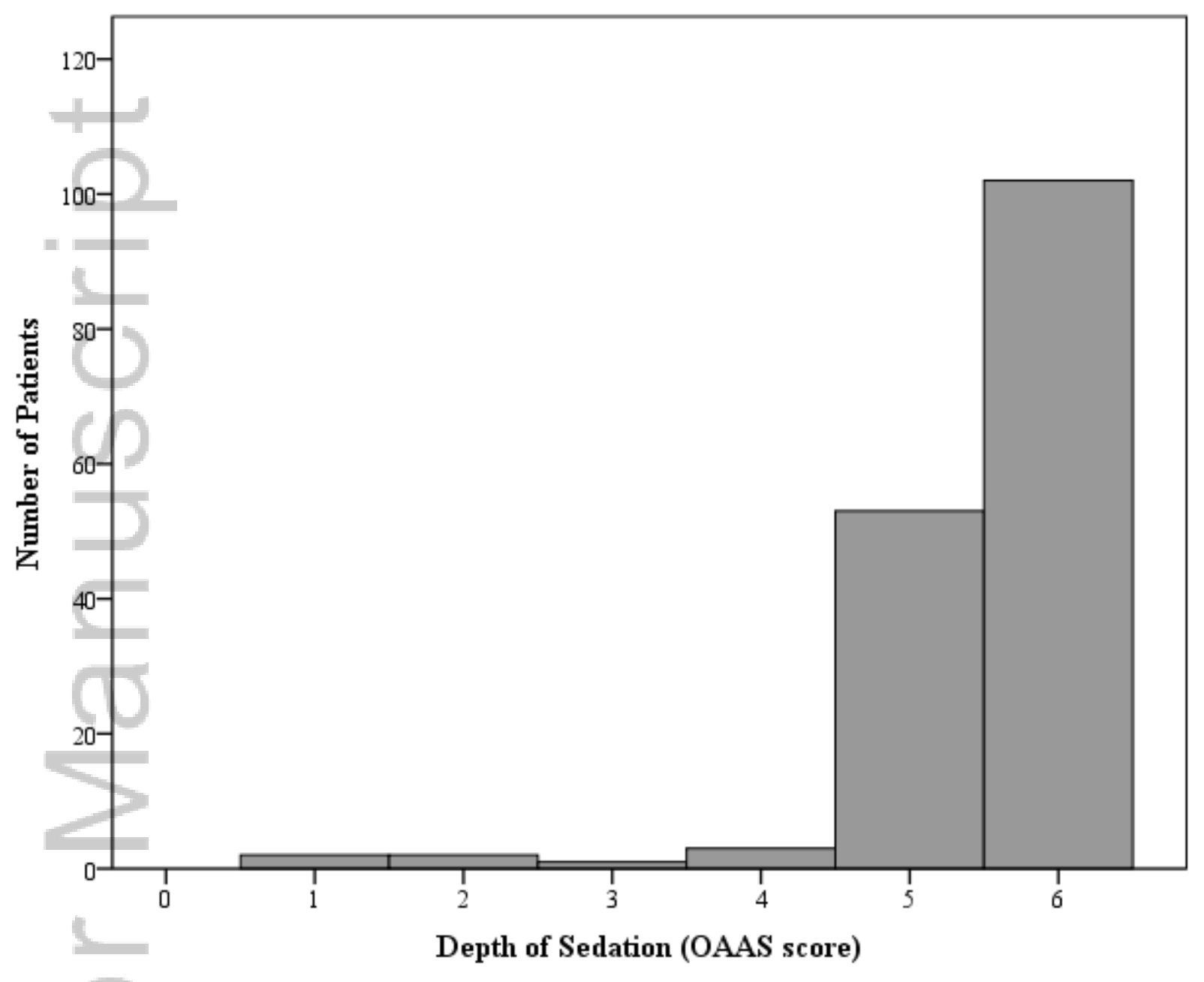

This article is protected by copyright. All rights reserved. 


\section{University Library}

\section{- M M N E R VA A gateway to Melbourne's research publications}

Minerva Access is the Institutional Repository of The University of Melbourne

\section{Author/s:}

Johnson, OG;Taylor, DM;Lee, M;Ding, J-L;Ashok, A;Johnson, D;Peck, D;Knott, J;Weinberg, L

Title:

Patient satisfaction with procedural sedation in the emergency department

Date:

2017-06-01

Citation:

Johnson, O. G., Taylor, D. M., Lee, M., Ding, J. -L., Ashok, A., Johnson, D., Peck, D., Knott, J. \& Weinberg, L. (2017). Patient satisfaction with procedural sedation in the emergency department. EMERGENCY MEDICINE AUSTRALASIA, 29 (3), pp.303-309. https://doi.org/10.1111/1742-6723.12762.

Persistent Link:

http://hdl.handle.net/11343/292714 